\title{
Treatment of Posterior Shoulder Dislocation in Obstetric Brachial Plexus Palsy Using Subscapularis Release and Tendon Transfer
}

\author{
Reda H Elkady, MD, Hossam A Fekry, MD \\ Department of Orthopedic Surgery, Faculty of Medicine, Zagazig University, Egypt \\ yousufmmkh@gmail.com
}

\begin{abstract}
Background: The muscle imbalance of the shoulder results in weak external rotation and abduction. Active internal rotation and adduction can cause glenohumeral joint deformity with late posterior dislocation.

Patients and Methods: In this prospective study from 2004 to 2009, thirty four patients, 18 females and 16 males with mean age of 4 years (1-7 years). The right side was affected in 19 cases while the left side was affected in 15 cases. All patients were suffering from obstetrical brachial plexus palsy (OBPP) with internal rotation contracture and defective shoulder abduction plus posterior dislocation or subluxation of the humeral head. These patients were treated with soft tissue release (subscapularis slide and anterior soft tissues release) with or without tendon transfer (latissimus dorsi \& teres major to infraspinatus).

Conclusion: The subscapularis release can provide objective functional benefit, but this degraded over time. The transfer of teres major and latissimus dorsi to infraspinatus is a useful procedure for correction of defective shoulder abduction and external rotation in (OBPP) as it increases the stabilizing action of the rotator cuff allowing the deltoid muscle to act with maximal force.
\end{abstract}

\section{INTRODUCTION}

The incidence of obstetric brachial plexus palsy (OBPP) is 1 to $4 / 1000$ live births, and about $50 \%$ of these cases have good recovery without late deformity. Partial recovery of the C5, C6, C7 roots gives muscle imbalance, and delay of recovery causes biceps muscle contracture ${ }^{\mathbf{1 - 3}}$. The residual muscle imbalance of the shoulder in the form of weak external rotation and abduction with active internal rotation and adduction can cause glenohumeral joint deformity with late dislocation posteriorly ${ }^{4-6}$. The advances in microvascular surgery and early reconstruction of the brachial plexus reduced the need for palliative treatment as rehabilitation by physiotherapy, orthosis, and braces which are difficult to apply in this young age and failure occurs in severe cases ${ }^{7}$.

For treatment of this deformity there were many surgical options, such as anterior release of contractures in internal rotators and adductors of the shoulder as in Sever operation ${ }^{8}$. Enhancing this technique tendon transfer of the latissimus dorsi and teres major to the lateral aspect of the humerus was added by L'Episcopo ${ }^{9}$. Later, the technique of transferring the latissimus dorsi and teres major to the rotator cuff was suggested by Hoffer et al ${ }^{10}$. Bone procedures as derotation osteotomy of the proximal humerus are available to correct these deformities. Pedicle and free muscle transfers in cases of paralytic shoulder are other options. The criteria of selection of the specific procedure were based on the age of the patient and the degree of glenohumeral deformity on the preoperative computed CT or MRI. As long as the glenohumeral joint is congruent, tendon and muscle transfer can be performed at a later date, but they should be considered at earlier times to maximize functional recovery ${ }^{11}$. Shoulder reconstruction expected to improve both arm appearance and some of the hand functions as reaching the head or mouth and raising the hand above the shoulder ${ }^{3}$. 
Treatment of Posterior Shoulder Dislocation in Obstetric Brachial Plexus Palsy Using Subscapularis Release and Tendon Transfer

The aim of this prospective study is to evaluate the results of 34 patients with OBPP treated surgically with anterior release and tendon transfer of teres major and latissimus dorsi.

\section{Patients And Methods}

In a prospective study from 2004 to 2009, thirty four patients, 18 females and 16 males with mean age of 4 years (1-7years). The right side was affected in 19 cases while the left side was affected in 15 cases. All patients were suffering from obstetrical brachial plexus palsy (OBPP) with internal rotation contracture and defective shoulder abduction with posterior dislocation or subluxation of the humeral head. These patients were treated with soft tissue release (subscapularis slide and anterior soft tissues release) with or without tendon transfer (latissimus dorsi \& teres major to infraspinatus).

Sixteen cases (47 \%) were delivered at hospital while eighteen cases (53\%) were delivered at home. fifteen cases (44 \%) had definite history of difficult labor , and five cases (14.7\%) were breech delivery. Two cases (5.9\%) had associated fracture clavicle. In 9 cases $(26.5 \%)$ the baby was the first child of his/her parents. Birth weight in 17 cases (50\%) was over $4 \mathrm{~kg}$ (3.6 to $4.5 \mathrm{~kg}$ ) which appear to be the most important risk factor. 32 cases $(94.1 \%)$ had no previous surgery and were treated by physiotherapy. only 2 cases $(5.9 \%)$ had primary microsurgical repair of the plexus. We found complete paralysis $\left(\mathrm{C}_{5}, \mathrm{C}_{6}, \mathrm{C}_{7}, \mathrm{C}_{8}, \mathrm{~T}_{1}\right.$ roots affected) in 21 cases $(61.8 \%)$ at the time of birth and 13 cases $(38.2 \%)$ were partial $\left(\mathrm{C}_{5}, \mathrm{C}_{6}\right.$ only affected. All cases 34 were suffering from medial rotation contracture, 21 cases $(61.8 \%)$ were dislocated and 13 cases (38.2\%) were subluxated. Standard plain X-ray of the shoulder and computerized tomography (CT) were routinely done for all patients for precise assessment of the deformity (Glenoid retroversion and degree of posterior subluxation of the humeral head). Follow up (CT) of both shoulders were performed for all 34 cases postoperatively. We used mallet ${ }^{12}$ grading and modified Gilbert systems ${ }^{13}$ for the shoulder function (Fig 1) \& (Table 1\&2)

Modified Mallet classification (grade $I=$ ne function, Grade $V=$ normal functiol

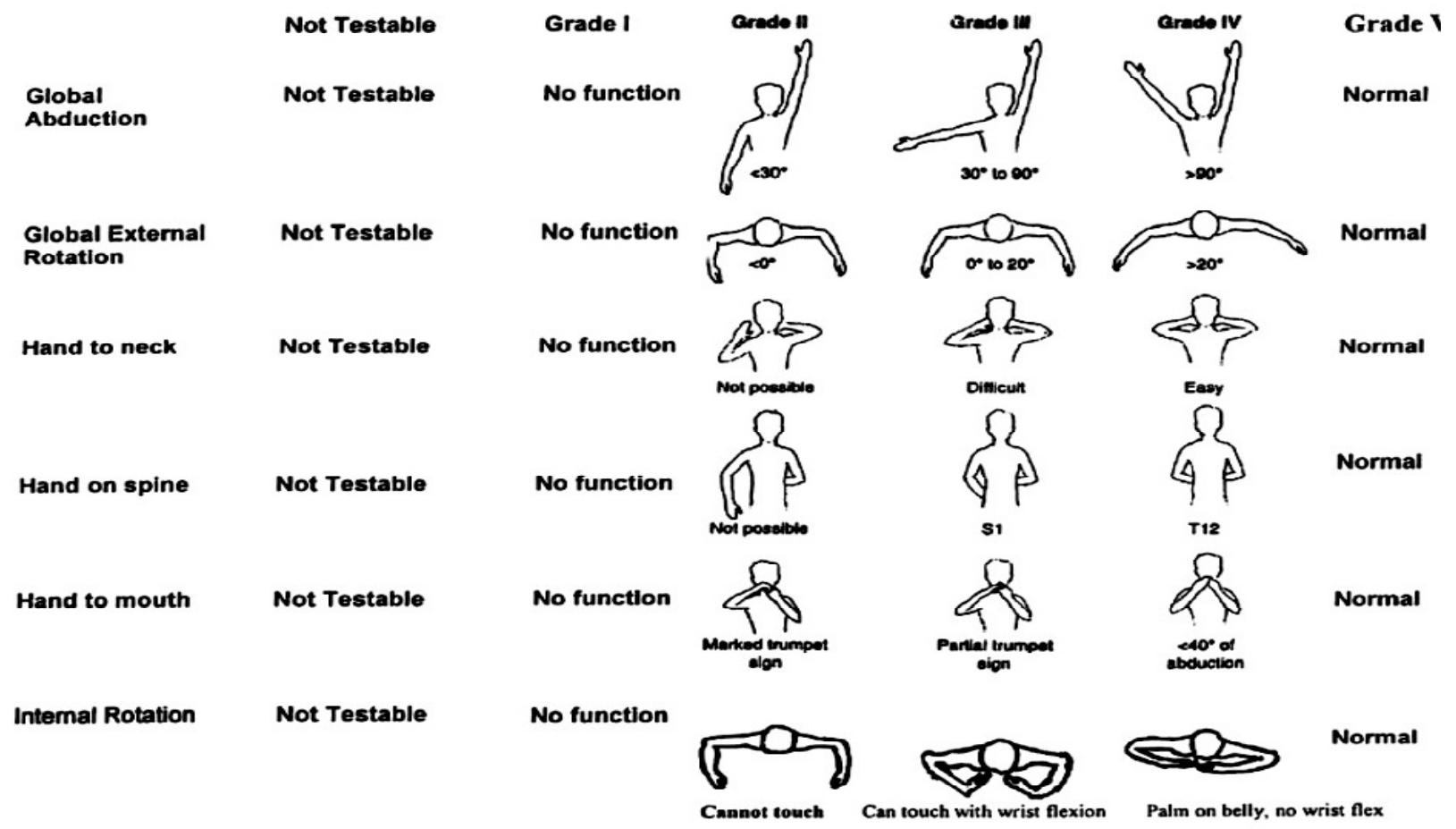

Fig1. Illustration of Mallet classification. A score of one represent no function, and a score of 5 represent full function. 
Treatment of Posterior Shoulder Dislocation in Obstetric Brachial Plexus Palsy Using Subscapularis Release and Tendon Transfer

Table1. The Mallet grading of function of the shoulder joint.

\begin{tabular}{|l|l|}
\hline Mallet grading & Description \\
\hline Grade I & Flail shoulder \\
\hline Grade II & $\begin{array}{l}\text { Active abduction < } 30 \\
\text { Zero degrees of external rotation } \\
\text { Hand to back of neck impossible } \\
\text { Hand to back impossible } \\
\text { Hand to mouth with marked trumpet sign }\end{array}$ \\
\hline Grade III & $\begin{array}{l}\text { Active abduction of } 30 \text {-90 } \\
\text { External rotation up to } 20 \\
\text { Hand to back of neck difficult } \\
\text { Hand to back with difficulty } \\
\text { Hand to mouth possible with partial trumpet sign }\end{array}$ \\
\hline Grade IV & $\begin{array}{l}\text { Active abduction over } 90 \\
\text { External rotation over } 20 \\
\text { Hand to back of neck easy } \\
\text { Hand to back easy } \\
\text { points, good function }=9-12 \text { points and Poor function < 9 points. (Nicolas et al., 2004) }\end{array}$ \\
\hline Hrade V & $\begin{array}{l}\text { Normal shoulder } \\
\text { Grade III gives } 2 \text { points, and grade IV gives } 3 \text { points. Excellent function = 15 }\end{array}$ \\
\hline
\end{tabular}

Table2. Modified Gilbert system.

\begin{tabular}{|l|l|}
\hline Stage & Function \\
\hline Stage 0 & Flail shoulder \\
\hline Stage I & Abduction or flexion to 45, no active lateral rotation \\
\hline Stage II & Abduction $<90$, lateral rotation to neutral \\
\hline Stage III & Abduction $=\mathbf{9 0 ,}$, weak lateral rotation \\
\hline Stage IV & Abduction $<120$, incomplete lateral rotation \\
\hline Stage V & Abduction $>120$, active lateral rotation \\
\hline Stage VI & Normal \\
\hline
\end{tabular}


Treatment of Posterior Shoulder Dislocation in Obstetric Brachial Plexus Palsy Using Subscapularis Release and Tendon Transfer

\section{Rationale of Treatment}

The aim of the operations was to relocate the dislocated glenohumeral joint and to alleviate secondary deformities arising from incomplete recovery following nonsurgical management or residual deformities following primary reconstruction.

All 34 patients underwent subscapularis release. Added tendon transfers were needed in 21 cases. Posterior capsulorraphy was done in three cases for residual glenohumeral subluxation.

\section{Technique for Subscapularis Release}

The patients were placed in lateral decubitus. The affected shoulder and torso were prepared to the mid-line anteriorly and posteriorly. A longitudinal incision was made along the lateral border of the scapula, and dissection was carried out down to the latissimus dorsi muscle, which was retracted inferiorly, and the inferior angle of the scapula was identified and stabilized with towel clips. The subscapularis muscle is readily identified and elevated in its entirety from the anterior surface of the scapula with use of electrocautery or a periosteal elevator.

Dissection was then performed in a subperiosteal fashion, progressing from the inferior angle upward. An external rotation force on the humerus was applied gently throughout the release to confirm adequate release of the muscle and elimination of the contracture. Care must be taken to avoid injury of the subscapular artery and nerve running anteromedial to the glenoid neck and anterior to the subscapularis muscle, and over the scapular notch. After complete release of the subscapularis muscle, the wound was closed over a suction drain.

\section{Technique for Tendon Transfer}

The patient is lying in lateral decubitus, with the arm is abducted $120^{\circ}$ and externally rotated. A curved wide C shaped incision following the lateral border of the scapula and the posterior margin and the deltoid 2-3 cm posterior to the posterior axillary fold to avoid tethering scar. After dissection of the deep fascia, the tendons were identified, and the latissimus dorsi tendon was released at its insertion at the proximal humerus. In our work, the tendon of latissimus dorsi was thin and weak in 3 cases (below 2 years of age) where the transfer of the latissimus dorsi was augmented by terse major muscle transfer as described by Edward et al $(2000)^{14}$.

To avoid injury of their neurovascular bundles, care was done to avoid excessive dissection on the under surface of the latissimus dorsi and teres major. The interval between the poster-inferior margins of the deltoid muscle and the rotator cuff was then developed, and with the arm maximally abducted and externally rotated, the released tendons of teres major and latissimus dorsi were sutured as superior as possible to the infraspinatus tendon. We always putted in mind that the tension of the transferred tendons should keep the arm in some abduction and external rotation.

At the completion of the operation, the arm was held in the appropriate position and a plaster body jacket, prepared before the operation, was applied and above elbow cast was applied and attached to the body jacket with the shoulder in 90 of abduction, full external rotation and 20 forward elevation in order to take pressure off the brachial plexus. One month postoperative a splint was applied full-time to maintain the arm in abduction and external rotation position for 1.5 months, removing it only to bathe and for gentle range-of-motion exercises, which are begun at six weeks. The patient then wears the splint only at night for an additional1.5 months to be discontinued six months postoperatively (Fig 2). 
Treatment of Posterior Shoulder Dislocation in Obstetric Brachial Plexus Palsy Using Subscapularis Release and Tendon Transfer

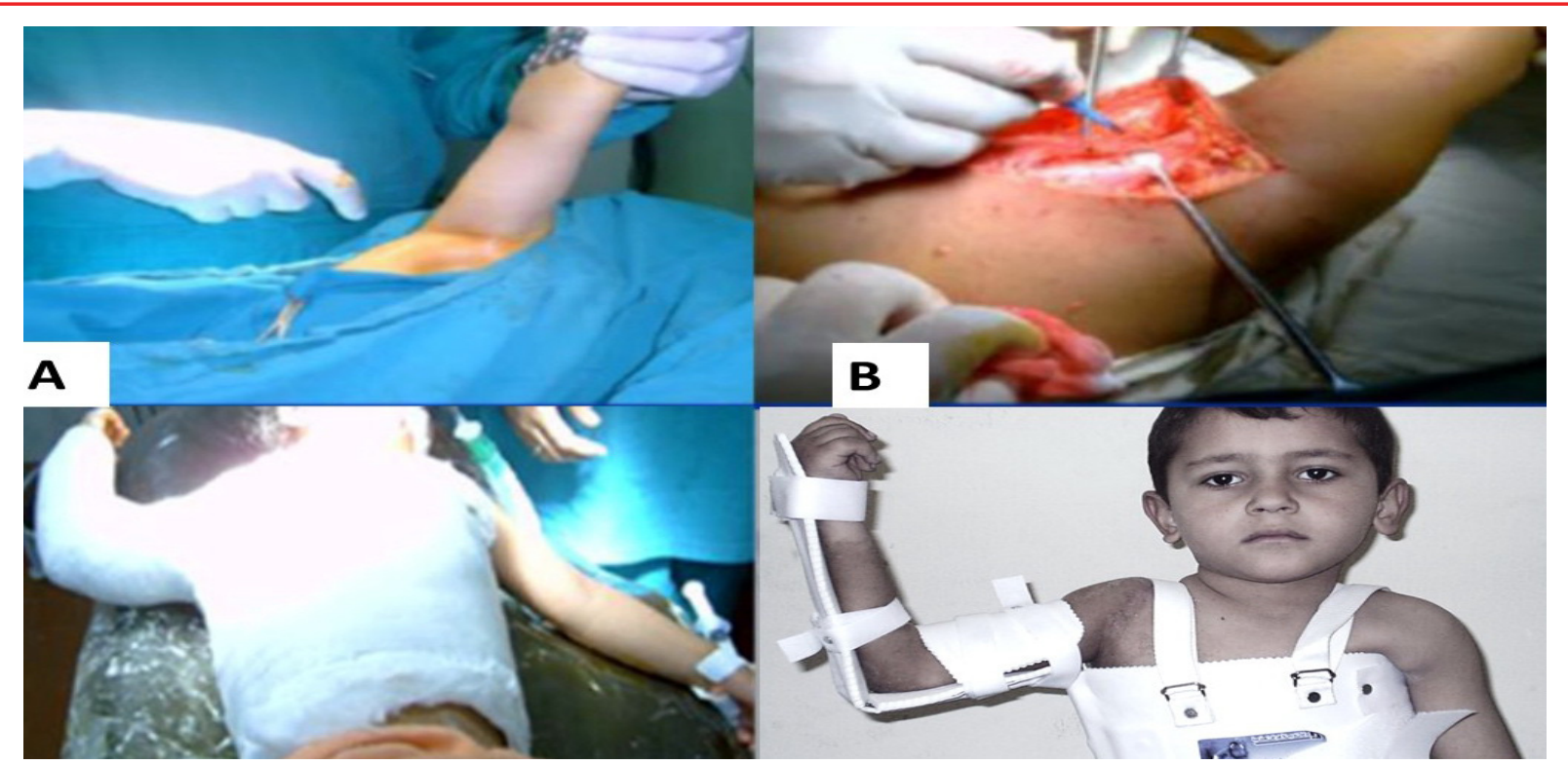

Fig2. Some stages in operative technique: A) position of the patient; B) posterior exposure of the tendons; C) plaster jacket; D) shoulder abduction splint.

\section{Statistics}

We used SPSS 17 program for windows: Results were expressed as mean \pm standard deviation for quantitative variables, and as percentages for qualitative variables. Paired T-test was used to determine the effect of surgery on shoulder motion.

\section{RESULTS}

The follow up ranged from 24 months to 62 months with an average of 30 months. The mean shoulder abduction in all patients was improved from $\left(85.9^{\circ} \pm 18.9 \mathrm{SD}\right)$ preoperative to $(132.0 \pm 18.7 \mathrm{SD})$ postoperative. The mean shoulder external rotation in all patients was improved from $\left(-17.9^{\circ} \pm 16.6 \mathrm{SD}\right)$ preoperative to $(66.5$ $\left.{ }^{\circ} \pm 14.9 \mathrm{SD}\right)$ postoperative $(\mathrm{P} \geq 0.001)$. The mean improvement of shoulder external rotation was 84.4 degrees, thus the average gain in shoulder external rotation was $37 \%$. The improvement in both abduction and external rotation was statistically significant (Table 3). With correlation between the age at surgery (in months) and the improvement of shoulder abduction and external rotation postoperatively, we found a highly significant negative correlation $(\mathrm{P} \geq 0.001)$ between age at surgery and average improvement of shoulder abduction and external rotation (chart 1) (i.e. the older the age at surgery, the less the improvement in shoulder range of abduction and external rotation (Fig 3\&4).

Table3. preoperative and postoperative range of motion (abduction and internal rotation)

\begin{tabular}{|l|l|l|l|l|}
\hline & Pre operative & Post operative & Paired t & P value \\
\hline Mean abduction \pm standard D. & $85.9 \pm 18.9$ & $132.0 \pm 18.7$ & 15.3 & $\leq 0.001$ \\
\hline Range & $60-130$ & $90-170$ & & \\
\hline Mean ext. Rot. \pm Standard D. & $-17.9 \pm 16.6$ & $66.5 \pm 14.9$ & 17.14 & $\leq 0.001$ \\
\hline Range & $-45-20$ & $40-90$ & & \\
\hline
\end{tabular}


Treatment of Posterior Shoulder Dislocation in Obstetric Brachial Plexus Palsy Using Subscapularis Release and Tendon Transfer

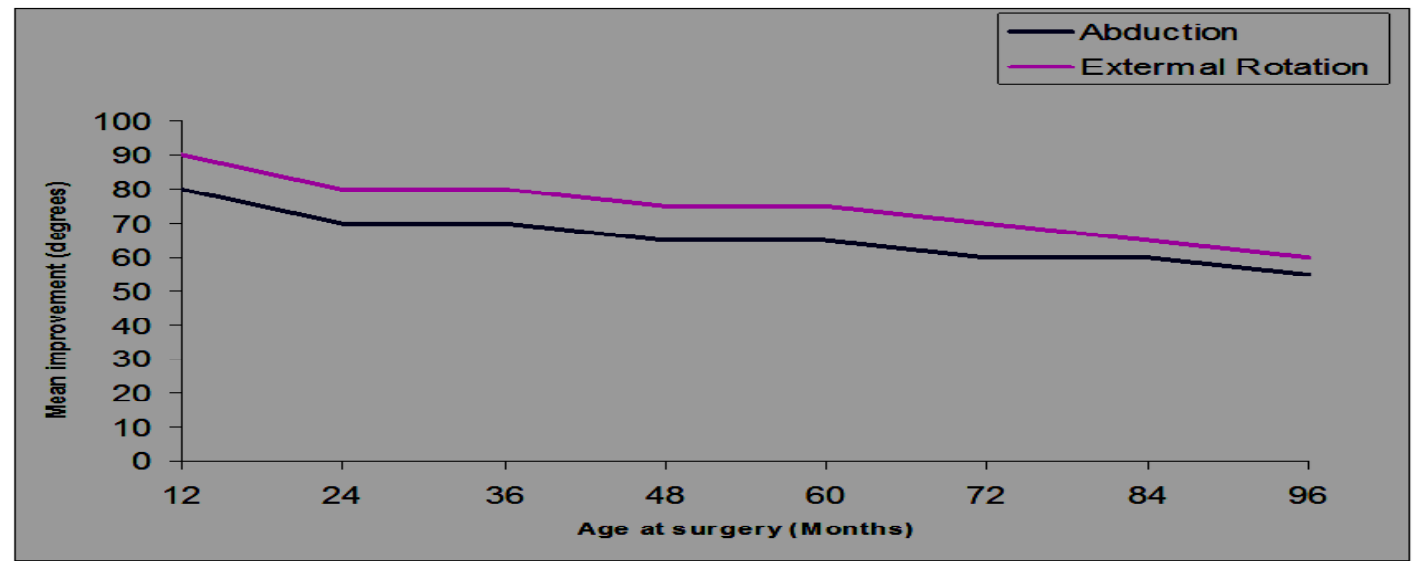

Chart1. The mean improvement of abduction and external rotation of the shoulder in relation to age

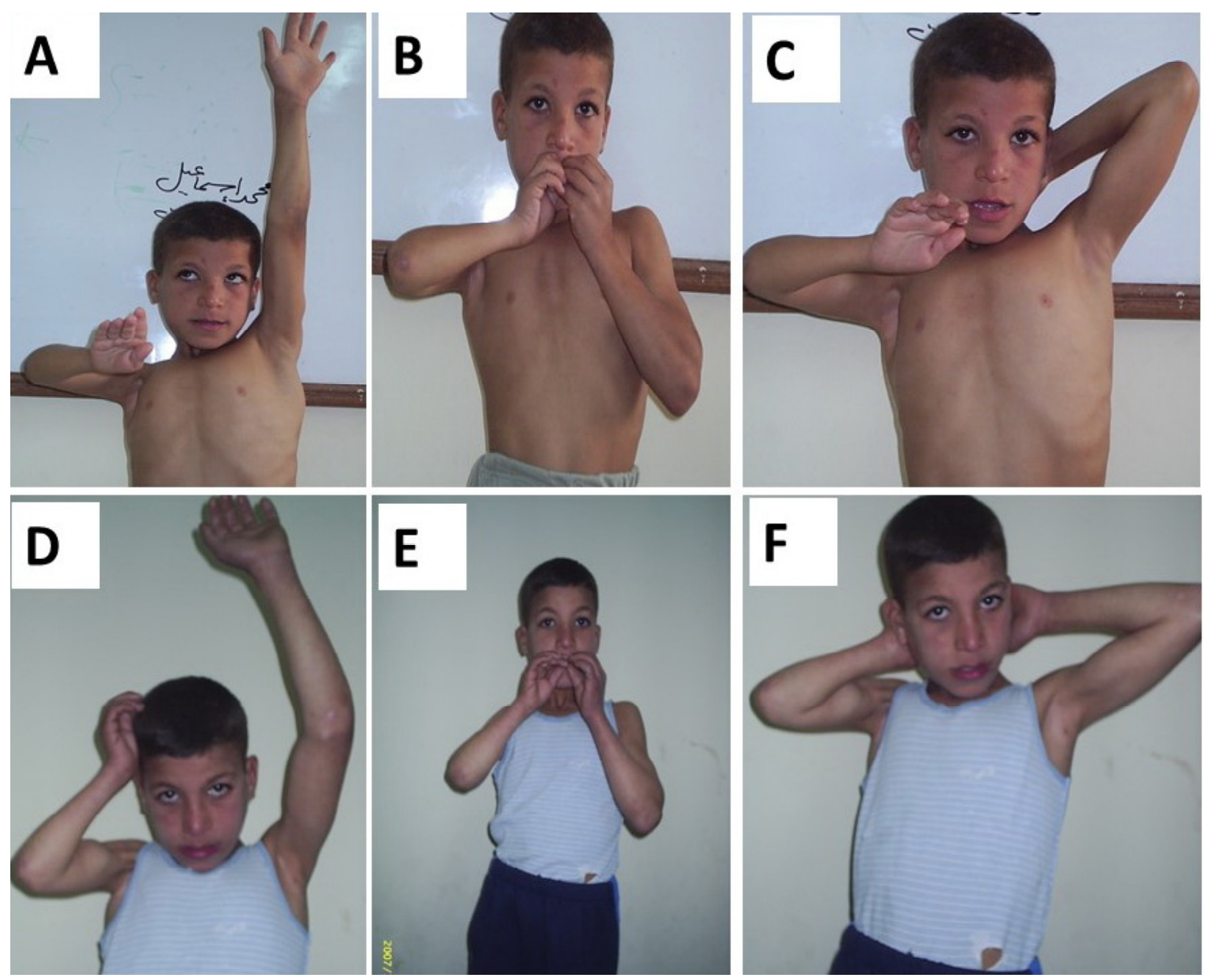

Fig3. case No. 7: $A \& B \& C)$ Preoperative range of motion; $B \& D \& F)$ the movements of the same patient after 2 years follow up. 
Treatment of Posterior Shoulder Dislocation in Obstetric Brachial Plexus Palsy Using Subscapularis Release and Tendon Transfer
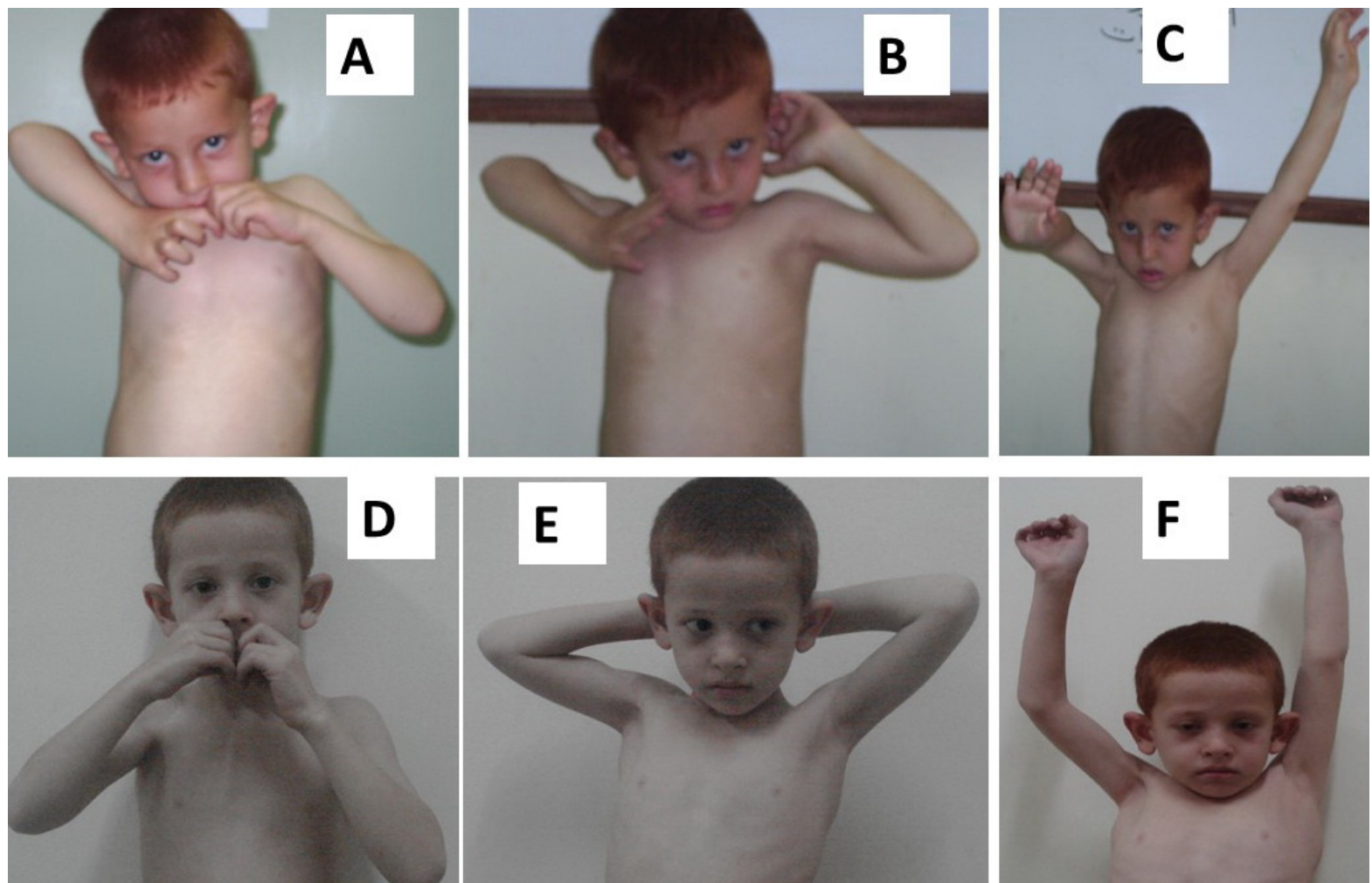

Fig4. Case No. 9: D\&E\&F) Preoperative range of motion; $B \& D \& F)$ the movements of the same patient after 2 years follow up.

The mean global Mallet score ${ }^{12}$ was improved from 7.1 \pm 1.0 SD (range from $6-9$ ) points preoperative to $13.2 \pm 0.8$ SD (range from 11- 15) postoperative. We had 29 cases with excellent score , 5 good, and none with poor score postoperative in comparison to 30 cases with poor score, 4 good, and none with excellent score preoperative (Table 4) .

Table4. Global Mallet score changes.

\begin{tabular}{|l|l|l|l|l|}
\hline & Pre-operative & Post-operative & Paired t & P \\
\hline Mean abduction \pm standard D. & $85.9 \pm 18.9$ & $132.0 \pm 18.7$ & 15.3 & $\leq 0.001$ \\
\hline Range & $60-130$ & $90-170$ & & \\
\hline Mean ext. Rot. \pm Standard D. & $-17.9 \pm 16.6$ & $66.5 \pm 14.9$ & 17.14 & $\leq 0.001$ \\
\hline Range & $-45-20$ & $40-90$ & & \\
\hline
\end{tabular}

Follow up computerized tomography (CT) of both shoulders was done one year postoperatively to measure the glenoid version and degree of subluxation of the humeral head. Statistically when correlating the relationship between age at surgery and CT changes, we found highly significant negative correlation ( $\mathrm{P} \leq 0.001)$ between age at surgery and the glenoid retroversion was found (i.e. the older the age at surgery, the higher is the degree of retroversion of the glenoid) (Fig 5\&6), however there was no significant correlation between age at surgery and the degree of posterior subluxation or dislocation of the humeral head. 
Treatment of Posterior Shoulder Dislocation in Obstetric Brachial Plexus Palsy Using Subscapularis Release and Tendon Transfer

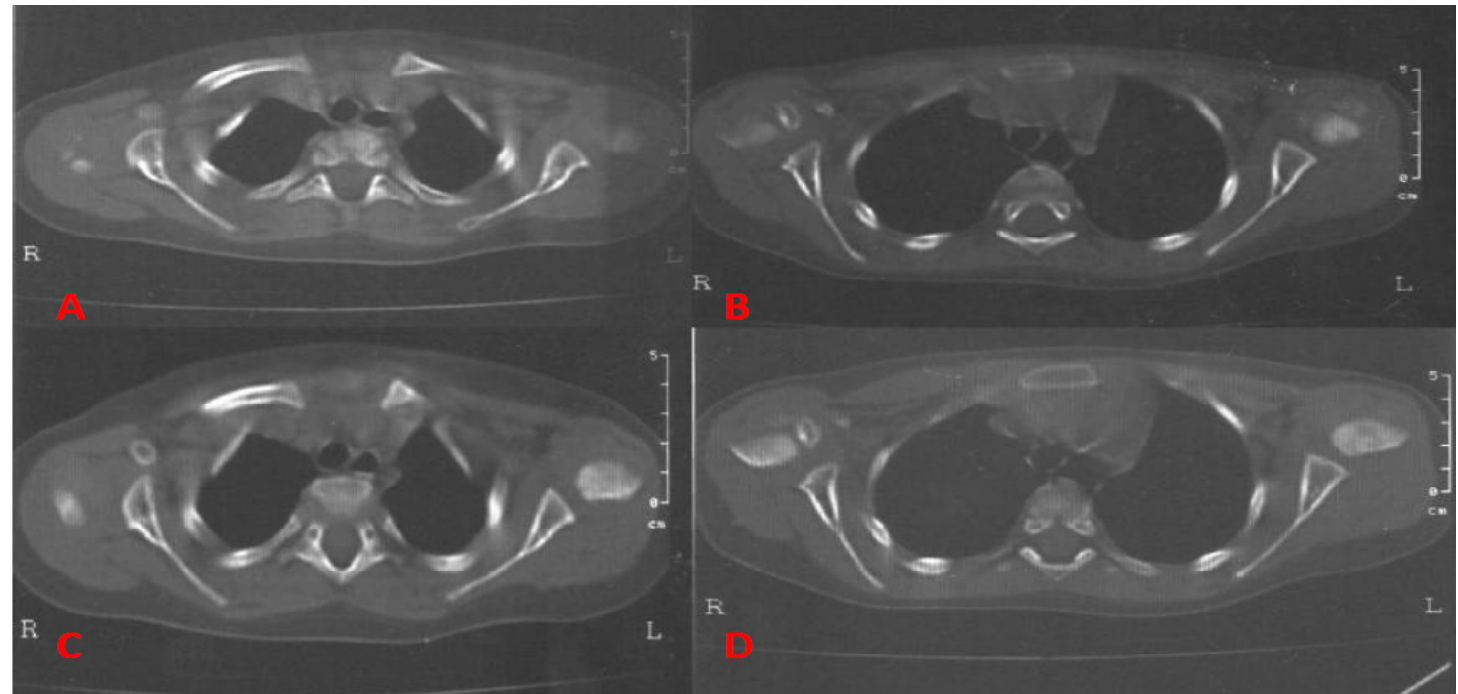

Fig5. CT scan of the patient No. 8 A\&C) Preoperative CT; B\&D) 1 year postoperative.

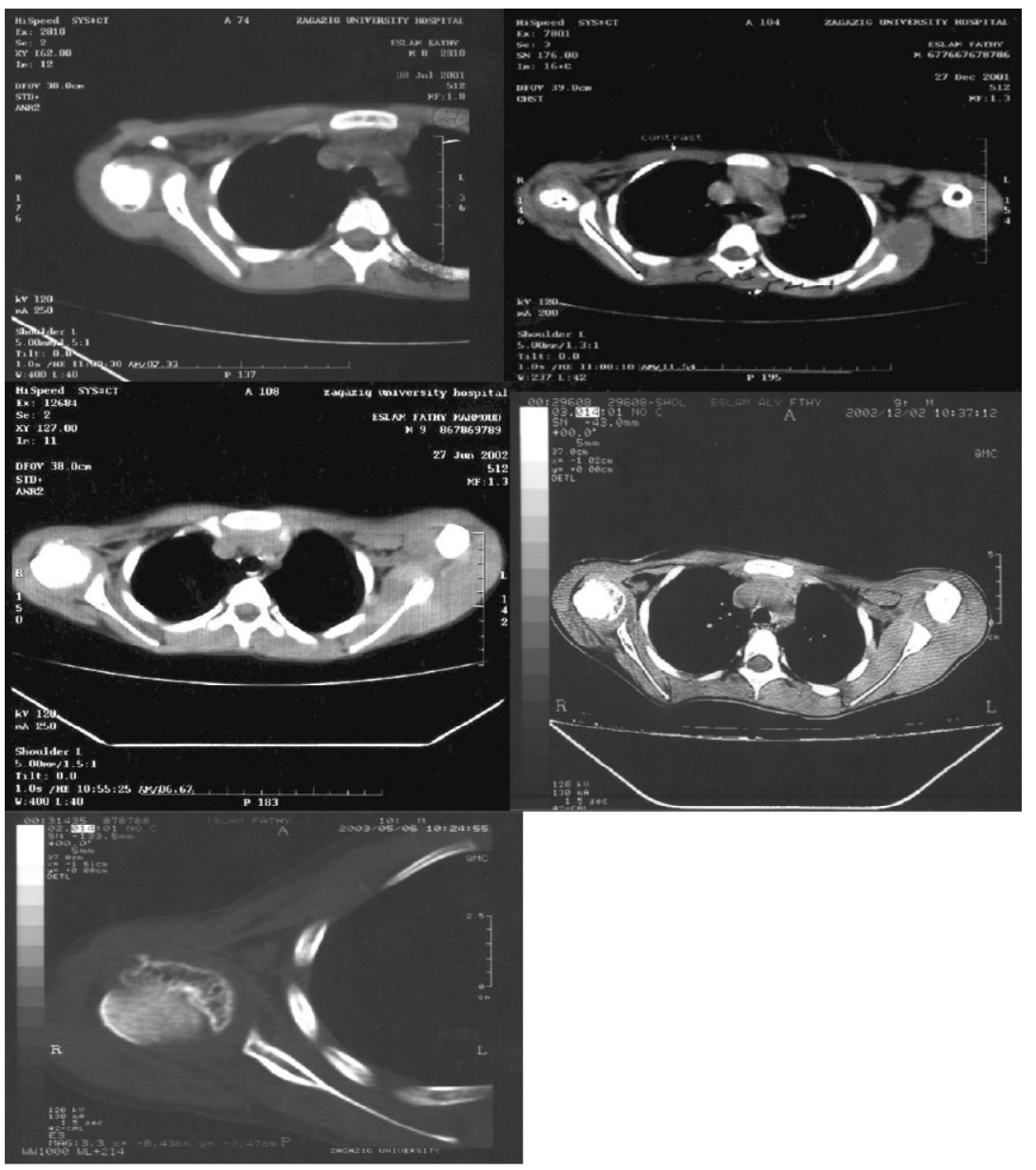

Fig6. Serial CT examination of patient No. 11 : A\&B) CT 6 months postoperative ; C\&D) 1 year follow up CT; E,F,G) 3 years follow up CT. 
The development of the glenohumeral joint in successive CT was characterized by the amount of glenoid version and the degree of humeral head subluxation in relation to the axis of the scapular spine. Prior to operation, the mean glenoid retroversion of the affected shoulder was $47.8^{\circ} \pm 8$ (range, $-60^{\circ}$ to $-35^{\circ} \pm$ ) and the mean humeral head subluxation was $8.82 \% \pm 7.7$ (Range, $0 \%$ to $25 \%$ ). At the end of the follow up period, the mean glenoid retroversion of the affected shoulder was $-8.7^{\circ} \pm 2.5$ (range, $-10^{\circ}$ to $-6^{\circ}$ ) and the mean humeral head subluxation of the affected shoulder was $46.6 \pm 1.3 \%$ (range, $45 \%$ to $49 \%$ ). The mean improvement in glenoid version was $39^{\circ}$ (range, $-60^{\circ}$ to $\left.-35^{\circ}\right)(p=0.012)$, and the mean improvement in humeral head subluxation was $37 \%(\mathrm{p}=0.03)$.

\section{COMPLiCATIONS}

Loss of the last degrees of internal rotation occurred in 10 cases $(29.4 \%)$ which were evident when the patient was asked to put his hand on his abdomen. However this loss was of little functional impairment. One case $(0.3 \%)$ had keloid and ugly scar. Superficial infection occurred in one case $(0.3 \%)$ however it was controlled with dressing and antibiotics. One case showed postoperative recurrence of posterior dislocation and was treated with proximal humeral osteotomy.

\section{DiscuSSION}

Posterior subluxation and dislocation occurs in about $20 \%$ of children with obstetric brachial plexus palsy and in Narakas groups 2 and 3 more than one third are so affected ${ }^{15}$. Internal rotation contracture is the most frequent and important secondary deformity of the shoulder in birth palsy. The problem is sometimes addressed by muscle release procedures such as the posterior subscapular slide or anterior subscapularis tendon lengthening operations. Once passive external rotation is improved, the child is later assessed for muscle transfers to reconstruct active external rotation if necessary ${ }^{16}$.

In this work we found good functional and clinical improvement provided by subscapularis muscle release with latissimus dorsi and teres major transfer. The mean global Mallet score ${ }^{12}$ was improved from $7.1 \pm 1.0$ SD (range from $6-9$ ) points preoperative to $13.2 \pm 0.8 \mathrm{SD}$ (range from 11-15) postoperative. We had 29 cases with excellent score, 5 good, and none with poor score postoperative in comparison to 30 cases with poor score, 4 good, and none with excellent score preoperative.

Some authors reported a decrease in postoperative gain over 10 years' follow-up; the final values were still higher than untreated cases because of the greater loss of external rotation and deterioration in glenohumeral congruence ${ }^{17}$.

Loss of external rotation and internal rotation deformity are indications for surgery releasing the subscapularis muscle first to restore external rotation range ${ }^{18}$. Some authors reported that tendon transfer of the teres major and/or latissimus dorsi insertions onto the proximal humerus or onto the infraspinatus muscle inhibits internal rotation but cannot recover significant active external rotation basically 9, 10,13. El-Gammal et al and Chuang et al added to this procedure lengthening of pectoralis major muscle to teres major transfer to the rotator cuff, reinserting the two extremities of the clavicular part of the pectoralis major laterally so as to enhance abduction 19, 20. External derotational osteotomy of the humerus is indicated only when glenohumeral incongruence prevents recovery of adequate joint mobility ${ }^{21,22}$.

Newman et al ${ }^{23}$, on a mean 4.7 years' follow-up of 13 patients with isolated subscapularis release, reported results comparable to those obtained with associated tendon transfer. In this study, isolated subscapularis release gave poorer results: six of the eight patients in question showed ER and modified Mallet scores below the mean values of the series as a whole, and two required later surgical correction. 
A great controversy was found in literature about the effect of the age of the patients at surgery on the final outcome. Waters et al ${ }^{16}$ believe that tendon transfer surgery slows shoulder joint impairment and corrects glenoid retroversion and posterior subluxation. Van der Sluijs ${ }^{4}$ in MRI study of 17 pathological shoulders found that $70 \%$ of patients under 5 months of age had normal shoulders, whereas $80 \%$ of those older than 5 months showed radiologic deformity. They concluded that late deformity is due to muscle imbalance. Consequently, early correction of imbalance should usefully postpone the onset of bone abnormality ${ }^{19,21}$. In Cohen $\mathrm{G}$ et al series $^{3}$, the patients over the age of 5 years get lower results than the younger patients, in the range of external rotation and modified Mallet score.

We agree with this conclusion as in this study when correlating the relationship between age at surgery and CT changes, we found highly significant negative correlation $(\mathrm{P} \leq 0.001)$ between age at surgery and the glenoid retroversion (i.e. the older the age at surgery, the higher is the degree of retroversion of the glenoid). We found also a highly significant negative correlation $(\mathrm{P} \geq 0.001)$ between age at surgery and average improvement of shoulder abduction and external rotation (i.e. the older the age at surgery, the less the improvement in shoulder range of abduction and external rotation). We found also that the various functional, clinical and scan data support the short- to medium-term benefit of this surgical indication.

\section{CONCLUSION}

Subscapularis release provided objective functional benefit, but this degraded over time. Teres major and Latissimus Dorsi to infraspinatus transfer is a useful procedure for correction of defective shoulder abduction and external rotation in (ОВРP). The basic advantages of this procedure over other tendon transfers are, it increases the stabilizing action of the rotator cuff thus allows the deltoid to act with maximal force, also in this position it increases both shoulder abduction and external rotation and it increases the lever arm of external rotation as the diameter of the head is larger than the diameter of the shaft.

\section{REFERENCES}

1. Waters P.M: Obstetric brachial plexus injuries: evaluation and management. J Am Acad Orthop Surg (1997), 5, pp. 205-214.

2. Pearl M.L. and Edgerton B.W: Glenoid deformity secondary to brachial plexus birth palsy. J Bone Joint Surg (1998), Am, 80 pp. 659-667.

3. Cohen G, Rampala V, F. Cohen A, Seringea R, and Wicarta P: Brachial plexus birth palsy shoulder deformity treatment using subscapularis release combined to tendons transfer; Orthopaedics \& Traumatology: Surgery \& Research (2010) 96, 334-339, doi:10.1016/j.otsr.2010.02.004.

4. Van der Sluijs J.A., Van Ouwerkerk W.J., De Gast A., Wuisman P.I., Nollet F. and Manoliu R.A: Deformities of the shoulder in infants younger than 12 months with an obstetric lesion of the brachial plexus. J Bone Joint Surg (2001), Br, 83 pp: 551-555.

5. Waters P.M., Smith G.R. and Jaramillo D: Glenohumeral deformity secondary to brachial plexus birth palsy. J Bone Joint Surg Am, 80 (1998), pp. 668-677.

6. Boome R.S. and Kaye J.C: Obstetric traction injuries of the brachial plexus. Natural history, indications for surgical repair and results. J Bone Joint Surg (1988) Br, 70 , pp. 571-576.

7. Waters P.M: Comparison of the natural history, the outcome of microsurgical repair, and the outcome of operative reconstruction in brachial plexus birth palsy. J Bone Joint Surg Am (1999), 81, pp. 649-659.

8. Clarke H.M. and Curtis C.G: An approach to obstetrical brachial plexus injuries, Hand Clin (1995), 11, pp. 563-580. 
Treatment of Posterior Shoulder Dislocation in Obstetric Brachial Plexus Palsy Using Subscapularis Release and Tendon Transfer

9. L'Episcopo J: Tendon transplantation obstetrical paralysis. Am J Surgery (1934), 25, pp. 122-125.

10. Hoffer M.M., Wickenden R. and Roper B: Brachial plexus birth palsies. Results of tendon transfers to the rotator cuff. J Bone Joint Surg Am (1978), 60, pp. 691-695.

11. Bennett JB, Allan CH: Tendon transfer about shoulder and elbow in obstetrical brachial plexus palsy. Instr. Course Lect. 2000; 49:319-32.

12. Mallet J: Paralysie obstétricale du plexus brachial. II. Traitement. Traitement des séquelles. Méthodes d'expression des résultats. Rev Chir Orthop (1972), 58 Suppl. 1 pp. 166-168.

13. Gilbert A., Romana C. and Ayatti R: Tendon transfers for shoulder paralysis in children. Hand Clin (1988), 4, pp. 633-642.

14. Edward TB, Baghian S, Faust DC and Willis RB: Results of Latissimus dorsi and teres major transfer to the rotator cuff in the treatment ofErb's palsy. J Pediatr Orthop 20: 375-379,2000.

15. Narakas A.O: Muscle transpositions in the shoulder and upper arm for sequelae of brachial plexus palsy. Clin. Neurol. And Neurosurg. 1993, 95 (Supplement): pp 89-91.

16. Waters P.M. and Bae D.S: Effect of tendon transfers and extra-articular soft-tissue balancing on glenohumeral development in brachial plexus birth palsy. J Bone Joint Surg (2005), Am, 87 pp. 320-325.

17. Guermazi M, Ghroubi S, Mezghanni M, Triki FE, Ellueuch MH: Suivi a long terme des epaules paralytiques obstetricales (a propos de 129 cas). Ann Readapt Med Phys 2004; 47:7-12.

18. Julia K. Terzis A, Zinon T. Kokkalis B: Primary and secondary shoulder reconstruction in obstetric brachial plexus palsy; Injury Int. J Care Injured, 2008, 39S, PP 5-14.

19. El-Gammal T.A., Saleh W.R., El-Sayed A., Kotb M.M., Imam H.M. and Fathi N.A: Tendon transfer around the shoulder in obstetric brachial plexus paralysis: clinical and computed tomographic study. J Pediatr Orthop (2006), 26, pp. 641-646.

20. Chuang D.C., Ma H.S. and Wei F.C: A new strategy of muscle transposition for treatment of shoulder deformity caused by obstetric brachial plexus palsy. Plast Reconstr Surg (1998), 101, pp. 686-694.

21. Waters P.M. and Bae D.S: The effect of derotational humeral osteotomy on global shoulder function in brachial plexus birth palsy. J Bone Joint Surg (2006), Am, 88 pp. 1035-1042.

22. Kirkos J.M. and Papadopoulos I.A: Late treatment of brachial plexus palsy secondary to birth injuries: rotational osteotomy of the proximal part of the humerus. J Bone Joint Surg (1998), Am, 80 pp. 14771483.

23. Newman C.J., Morrison L., Lynch B. and Hynes D: Outcome of subscapularis muscle release for shoulder contracture secondary to brachial plexus palsy at birth. J Pediatr Orthop (2006), 26, pp. 647-651.

Citation: Reda H Elkady, MD, Hossam A Fekry, MD. "Treatment of Posterior Shoulder Dislocation in Obstetric Brachial Plexus Palsy Using Subscapularis Release and Tendon Transfer". American Research Journal of Orthopedics and Traumatology. 2017; 2(1): 1-11.

Copyright (c) 2017 Reda H Elkady, MD, Hossam A Fekry, MD. This is an open access article distributed under the Creative Commons Attribution License, which permits unrestricted use, distribution, and reproduction in any medium, provided the original work is properly cited. 